\title{
Study of the efficiency of drying grass seeds for forage crops on a rotary dryer
}

\author{
V.A. Smelik ${ }^{*}, A . N$. Perekopskiy, A.V. Dobrinov, and S.V. Chugunov \\ Federal Scientific Agroengineering Center VIM, branch in Saint Petersburg, Saint Petersburg, Russia
}

\begin{abstract}
In many countries of the world with high climate humidity, grass seeds after their harvesting cannot be preserved without artificial drying. The artificial drying process is associated with high energy costs, and its regimes should not reduce the sowing quality of seeds. Therefore, it is of particular importance to determine the most suitable drying regimes for seeds. For this purpose, for the conditions of seed farms in the NorthWest of the Russian Federation, experimental studies were performed to obtain information on the parameters and modes of drying seeds of perennial grasses for their various initial states and conditions. Experimental studies were performed on a rotary dryer during the drying of meadow fescue seeds. The experimental data were analyzed in Microsoft Excel 2010 using the methods of mathematical statistics. The obtained mathematical dependencies made it possible to establish that the effective modes of drying the seeds of the studied culture are provided during their layer-by-layer unloading from the drying chamber. Moreover, the lower layer of seeds should be unloaded every 2.5 hours of drying, while adding to the upper layer of the drying chamber a new volume of seeds equal to the unloaded one.
\end{abstract}

\section{Introduction}

Perennial grasses form the basis of animal feed in many countries around the world. The quality and condition of perennial herbage directly depend on the quality of the seed. To maintain the productivity of perennial herbage, agricultural enterprises should be provided with their own seed material, adapted in terms of biological characteristics to local cultivation conditions. The use of zoned selection seeds for sowing makes it possible to increase the yield of grasses by up to $10 \mathrm{~kg} / \mathrm{ha}[1,2,3]$.

The experience of importing grass seeds from various regions of the country, including the EU, has shown their inefficiency for seed production. The sown areas in the North-West zone of the Russian Federation, sown with grasses that were brought from a number of European countries, as well as from the south of our country, did not provide the required productivity, while the death of certain types of grasses was quite often observed.

To meet the needs of livestock enterprises in forage from perennial grasses, it is necessary to organize their seed production, considering the biological characteristics of the cultivation conditions and in a sufficient quantity for consumers. The issues of post-harvest

${ }^{*}$ Corresponding author: smelik_va@mail.ru 
processing of seeds before storing them for storage are also important, especially for regions of increased moisture.

In North-West Russia, seeds of high-moisture herbs cannot be preserved without artificial drying. Therefore, it is of particular importance to determine the most suitable drying regimes for seeds.

Drying is an integral part of the process of producing grass seeds in various countries of the world $[4,5,6]$. Due to bad weather conditions, almost all grass seeds in the Nordic countries should be dried. Therefore, many research projects of leading research centers and manufacturing companies are devoted to solving various problems associated with the drying processes of various agricultural crops, including grass seeds [7, 8, 9].

In the whole technology of grass seed production, the most important and energyconsuming. is the process of drying them, associated with the process of removing excess moisture at the optimum permissible temperature conditions. Sufficiently studied modes of drying grain crops cannot be mechanically used for drying grass seeds because of the significant difference in their physical and mechanical properties. Small grass seeds during convective drying, due to the lower duty cycle, create great resistance to the movement of the coolant. And the aerodynamic properties of grass seeds do not allow the coolant to be supplied at a higher speed in order to avoid losses. These and other features complicate and complicate the drying process [3, 10-12].

Today, dryers for seeds of perennial grasses of the following types are widely used: conveyor, rotary, floor and drum ones. When using floor dryers, labor costs increase sharply, since they are not sufficiently mechanized. In turn, drum dryers are less demanding on the cleanliness of the initial heap, but at the same time, due to the complexity of the design, their production was closed.

In connection with these circumstances, for the most part, at agricultural seed-growing enterprises for drying grass seeds, dryers of two types are purchased: conveyor and carousel $[3,4]$. They are versatile, relatively simple in design and operation, and allow mechanization of all basic processes. However, up to now there are still questions on the choice and substantiation of the most effective parameters and modes of drying grass seeds in these dryers.

In this regard, the purpose of this study was to conduct experimental studies and, on the basis of the information obtained, establish effective modes of drying seeds of perennial grasses on a rotary dryer in the conditions of seed farms in the North-West of Russia, characterized by unfavorable harvesting conditions in terms of humidity.

\section{Materials and methods}

The studies were performed in the seed-growing enterprises of the Leningrad region, JSC Volkhovskoe, Volkhovsky district, and LLC Novoladozhsky, on a heap of increased initial moisture content without preliminary purification. For drying grass seeds, an SKM-0.5 dryer was used, designed for low-flowing materials [4].

The drying process in a rotary dryer is as follows. The raw material delivered for drying from the vehicle, trailer or car body is unloaded into the receiving hopper and fed into the drying chamber by the loading conveyor. A preheated coolant is blown under the perforated platform of the drying chamber of the rotary dryer by a fan. Which, passing the layers of grass seeds, heats them and takes away excess moisture. As a result of heat and mass transfer, the seeds are dried, and the heat carrier is saturated with moisture and removed from the drying chamber. Due to the fact that the heat carrier will have the greatest moisture-absorbing capacity at the entrance to the drying chamber, the seeds of the lower layers dry out faster and are unloaded by a belt conveyor for further processing. 
During the experiment, a number of basic indicators were analyzed: the temperature of the coolant on various layers of the drying chamber, the initial and final temperatures of grass seeds, as well as their moisture content.

Herewith, samples of grass seeds were taken, their moisture content was determined pursuant to the requirements of GOST 13586.3-83 and GOST 13586.5-93.

Samples of samples in order to determine the values of temperature and moisture content of seeds before and after loading the dryer were taken from the flow of seeds falling from the loading device and the unloading screw of the dryer. A 0.5 liter plastic container with a lid was used for this. To measure the temperature of the seeds in the layer, the samples were taken with a sampling probe to a depth of $0.5 \mathrm{~m}$ and poured into plastic containers with a volume of at least 0.51 . The seed temperature was measured with a T7 thermometer (Russia); the moisture content of control seed samples was measured using a Wile 35 moisture meter (Finland).

During the experiment, the temperature of the coolant was controlled by a digital thermostatic element installed in the air duct, which automatically regulated the operating temperature and the temperature of the seeds by automatically turning off the burner in case of overheating. The temperature of the coolant and, accordingly, its humidity were measured with a TKA-PKM hot-wire anemometer (model 60, RF) at the entrance to the drying room, in the supply air duct, and also in different layers of seeds.

The performance of the drying unit (actual) was measured based on the mass of sampling of the dried heap of seeds for a certain period. The experiment included at least five such samples. At each such cutoff, the seeds were loaded into a special container, and then weighing took place (AB-875 scales). To determine the cut-off time, a SOSpr-26-2000 stopwatch was used.

As a result, the basic $\mathrm{Q}_{\mathrm{d}}$ productivity (dry) in $\mathrm{kg} \mathrm{h}^{-1}$ was determined as follows (1) [4]:

$$
Q_{d}=60 \frac{\sum_{i=1}^{n} M_{i}}{\sum_{i=1}^{n} T_{i}},
$$

where $M_{i}$ is the mass of seeds of the $i$ th sample, $\mathrm{kg}$;

$T_{i}$ is the flow time of the $i$-th sample, $\mathrm{s}$.

The moisture content of the seeds in the dryer was measured in real time with a FAUNA-P moisture meter (Russia) pursuant to the capacitive principle of moisture measurement. This is a microprocessor that displays the percentage of moisture, temperature and the name of the studied culture on a liquid crystal display. The device is equipped with two humidity and temperature sensors.

The moisture meter (Fig. 1) was a monoblock with a front panel with a liquid crystal display and a command button, as well as a battery compartment at the bottom of the device.

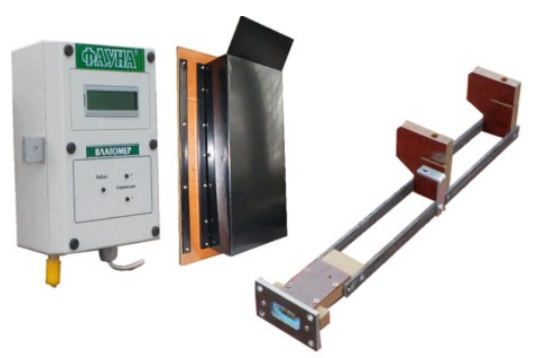

Fig. 1. General view of the Fauna-P flow moisture meter with humidity and temperature sensors. 
Experimental studies of the drying process in a rotary dryer were performed when drying meadow fescue seeds with an initial (initial) moisture content of $22.2 \%$. The coolant temperature was $55{ }^{\circ} \mathrm{C}$. Drying time of seeds to final moisture was 2 hours (120 minutes). In connection with the design features of the rotary dryer, in order to study the process of changing the parameters of seeds in different parts of the drying chamber, the seed layer was divided into zones pursuant to its height, each $0.14 \mathrm{~m}$ thick. The first zone $-I$ from 0 to $0.14 \mathrm{~m}$, the second - zone $I I$ from 0.14 to $0.28 \mathrm{~m}$ and the third zone $I I I$ from 0.28 to $0.42 \mathrm{~m}$. In addition, the parameters of the seeds were measured in the upper and lower layers of the drying chamber.

In the course of the experiment using a rotary-type dryer, the influence of three important and significant factors was determined, such as the temperature of the coolant in the duct, the flow rate of the coolant, and the thickness of the seed layer on the drying process. The initial values of the levels of factors are determined on the basis of previously conducted experiments and analytical studies of a number of literary sources $[3,13,14]$.

\section{Results and discussion}

Due to the fact that initially a pile of seeds has a high initial moisture content, it is necessary that the temperature of the coolant during the drying process be within the range of up to $50-55^{\circ} \mathrm{C}$ in order to avoid the formation of cracks on the seeds. The presence of cracks on the surface negatively affects the period of storage and germination, which ultimately does not allow farms to have highly reproductive seeds at the stages of selection and seed production.

During warm weather with the presence of the sun, it is possible to dry grass seeds quite successfully without heating the coolant. In one of the farms in the North-West region of the Russian Federation, in JSC "Volkhovskoe", the drying of seeds was successfully performed without using a heat generator, only ambient air was used, while a heap of fescue seeds with meadow moisture of $21.4 \%$ was qualitatively dried within 7 hours to a standard humidity (13.8\%) (Fig. 2).

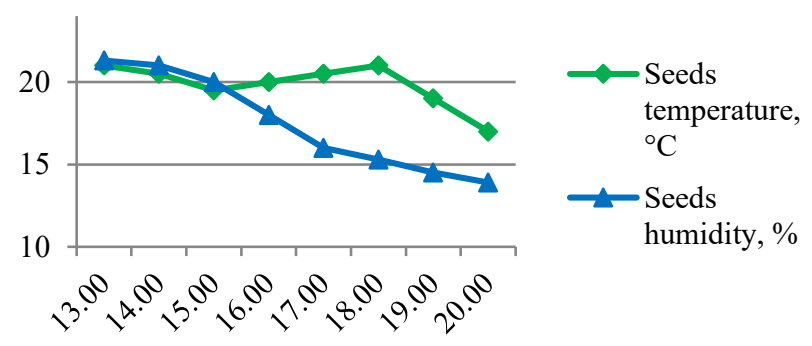

Fig. 2. The process of changing temperature $\left({ }^{\circ} \mathrm{C}\right)$, humidity $(\%)$ depending on the daily drying time (h) of meadow fescue seeds.

If the combine harvesting of seeds is performed in the daytime up to 1 p.m., then during drying there is a good opportunity to save fuel, which is spent on heating the coolant. In this case, only electricity is consumed to drive the fan.

In the course of experimental studies, it was established that as the heated coolant passes through the layers of seeds, the temperature of heating the seeds decreases. As a result, there is a decrease in the drying speed from the lower layers to the upper ones (table). 
Table 1. Results of experimental studies of the process of drying grass seeds to a rotary dryer.

\begin{tabular}{|c|c|c|c|c|}
\hline \multicolumn{3}{|c|}{ Drying zones by layers } & \multicolumn{2}{c|}{ Results of measurements } \\
\cline { 2 - 3 } Designation & \multicolumn{2}{|c|}{ Thickness of layer, $\mathrm{m}$} & \multirow{2}{*}{ Temperature, $\mathrm{t}, \mathrm{C}^{\mathrm{O}}$} & Humidity \\
\cline { 2 - 3 } & from & to & & 14.1 \\
\hline Low & 0 & 0.01 & 49.2 & 15.9 \\
\hline I & 0 & 0.14 & 44.6 & 21.2 \\
\hline II & 0.14 & 0.28 & 36.2 & 22.7 \\
\hline III & 0.28 & 0.42 & 24.1 & 23.3 \\
\hline Upper & 0.42 & - & 20.4 & \\
\hline
\end{tabular}

As a result of the studies performed, it was found that the temperature of the seeds in the layer of the I-th zone at a steady state of the temperature of the coolant, already 30 minutes after the start of drying, becomes $12{ }^{\circ} \mathrm{C}$ lower. The temperature of the seeds in the layer of zone II reached $36.2^{\circ} \mathrm{C}$. In the layer III-th zone the temperature of the seeds after 1 hour of drying was $22{ }^{\circ} \mathrm{C}$.

The results of the experiments made it possible to conclude that, depending on the speed, the drying process of seeds at different layers in height is not the same, while the drying time increases from the lower layer to the upper one (Fig. 3).

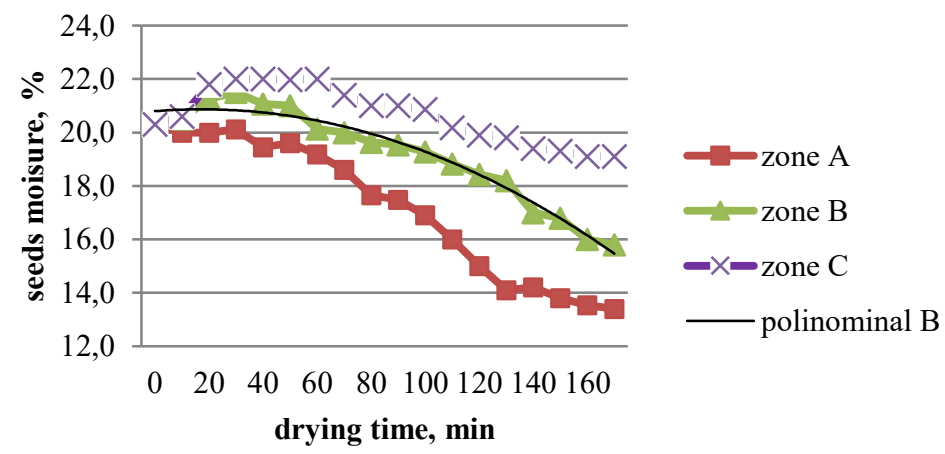

Fig. 3. The process of changing the moisture content of meadow fescue seeds in zones (I, II, III) at an initial moisture content of $20.2 \%$

As a result of processing the experimental information, mathematical dependences of the change in the moisture content of seeds $\mathrm{W},(\%)$ on the drying time $\mathrm{t}$, (min) were obtained. So, for a layer of seeds $0.14-0.28$ (zone $I I$ ), the indicated dependence has the form:

$$
\mathrm{W}=20.69+0.1264 \cdot \mathrm{t}-0.0231 \mathrm{t}^{2}
$$

The results obtained made it possible to optimize the drying process (Fig. 3) and to propose to remove dried seeds from the lower layer from the drying chamber every 2.5 hours by means of an unloading conveyor. After that, the upper layers move to the lower ones, and a new batch of wet seeds is loaded into the freed upper layer.

The process of drying grass seeds in the drying chamber of the rotary dryer takes place in two stages. Initially, moisture from the lower layers of the seeds moves to the upper ones, moistening them, and then it is removed as it heats up and reaches an equilibrium moisture content with a moisture-saturated heat carrier. Therefore, it is necessary to maintain the optimal layer thickness in the drying chamber, since at high values in the upper layers, the seeds are moistened, and not dried. This occurs only when the temperature 
of the seeds is below the temperature of adiabatic saturation of air, corresponding to the completion of the drying process of seeds $[3,6]$.

\section{Conclusions}

In the North-West region of Russia, the seed heap arriving at the post-harvest processing point, as a rule, has a high humidity. To ensure the preservation of the conditioned properties of seeds, it is necessary to organize a high-quality reception and their immediate drying.

It is necessary to ensure the optimum thickness of the seed layer in the drying chamber, depending on the parameters of the heat carrier and the moisture content of the seeds.

The optimal thickness (height) of the seed layer in the drying chamber allows full use of the heat carrier (saturate it with moisture), which ensures the most efficient drying of seeds in terms of energy consumption

\section{References}

1. E. Kubeev, V.A. Smelik, E3S Web of Conferences. VIII International Scientific and Practical Conference of "Innovative technologies in science and education" (ITSE 2020) 03006 (2020)

2. Forage Seed Processing Line, http://www.petkus.com

3. A. N. Perekopskii, S. V. Chugunov, Technologies, machines and equipment for mechanized crop and livestock production, 91, 126 (2017)

4. A. N. Perekopskiy, Rural Machine Operator, 5, 6 (2015)

5. R. Stanisavljević, D. Djokić, J. Milenković, D. Terzić, V. Stevović, D. Tomić, D. Dodig, Zemdirbyste-Agriculture, 101(2), 196 (2014)

6. O. I. Gaponyuk, M. V. Ostapchuk, G. M. Stankevich, I. I. Gaponyuk, Active ventilation and drying of grain (Odesa: VMV, 2014)

7. R. Stanisavljević, J. Milenković, D. Djokić, D. Terzić, D. Petrović, L. Djukanović, D. Dodig, Plant Soil and Environment, February, 59(1), 37 (2018)

8. P. Savinyh, Y. Sychugov, V. Kazakov and S. Ivanovs, 17th Int Sci Conf "Engineering for Rural Development", 17, 124 (2018)

9. J. R. Rasi, M. Neto, R. Bernardo, Int. J. Innov. Educ. Res., 9, 410 (2021)

10. C. Li, B. Li, J. Huang, C. Li, Developing an online measurement device based on resistance sensor for measurement of single grain moisture content in drying process, 20, 4102 (2020)

11. S. R. Parde, D. S. Jayas, N. D. G. White, Sciences Des Aliments, 23(5), 589 (2003)

12. Development of Moisture Removal Process, Energy Consumption and Control of a Grain Dryer (2016-2019) https://ec.europa.eu

13. T. Jokiniemi, M. Hautala, T. Oksanen, J. Ahokas, Parallel plate heat exchanger for heat energy recovery in a farm grain dryer Drying Technology, 34(5), 547 (2016)

14. Safe and Secure Supply of Grain with Innovative Resource-Efficient Drying, Handling and Storage 2019-2020 (Research project of RISE Research Institutes of Sweden AB Livsmedelsacceleratorn, Agrifood and Bioscience, Göteborg), https://www.vinnova.se 